\title{
The Future of Sustainable Intensification of Rice-Potato Agri-Food Systems in Asia
}

\author{
Marcel Gatto ${ }^{1}$, Jean Balié2 ${ }^{2}$ Guy Hareau ${ }^{3}$
}

December 13, 2021

1. International Potato Center, Tu Liem, Hanoi, Vietnam

2. International Rice Research Institute, Los Banos, Philippines

3. International Potato Center, Lima, Peru

This document is part of a series of short papers on "The Future of X", produced as part of foresight-related research supported by the CGIAR Research Program on Policies, Institutions, and Markets, and edited by Keith Wiebe (IFPRI) and Steven Prager (Alliance of Bioversity and (IAT). These short papers are intended to provide a focused, forward-looking perspective on key issues to support discussion on food, land, and water systems transformation. We thank two anonymous reviewers for their comments on an earlier draft.

This is an accepted version presented as a pre-print. It is currently undergoing final revision, editing, and production. A final version will be made available at http://foresight.cgiar.org.

\section{What is the issue?}

Agricultural production needs to drastically increase to feed a rapidly growing population. At the same time, arable land is shrinking due to urbanization and the adverse effects of climate change [1,2]. By 2050, potato demand in Asia is predicted to increase by $40 \%$ [3], where it is already a key staple, after cereals. This calls for an intensification of agricultural production which cannot be achieved in a sustainable way with conventional agricultural practices [4]. Intensification of conventional agricultural practices requires increased inputs that have potentially devastating negative effects on the environment and its ecosystem services [5]. Conventional agriculture practices release carbon dioxide in the atmosphere that causes climate change. In fact, one-third of the global carbon dioxide emissions come from agriculture and food systems [6]. At the same time, many conventional farming practices such as irrigation, flooding, or tillage reduce natural soil carbon levels [7].

Sustainable farming practices - often referred to as conservation agriculture - have the potential to mitigate the negative environmental effects of conventional agriculture practices. For example, zero/minimum tillage with residue retention reduces $\mathrm{CO}_{2}$ emission and has been adopted on some 2.5 million ha in Asia [8]. Similarly, the process of alternate wetting and drying (AWD) reduces GHG emissions in rice production by 30-70\% [9]. Yield and economic gains, however, remain clear drivers of practice adoption [10]. Despite the need for sustainable intensification of agricultural production, evidence of the magnitude of land suitability for 
intensification, extent of adoption of conservation agricultural practices, estimations of reduced carbon footprints, and understanding of trade-offs and wider socio-economic implications, are lacking.

\section{What research has been done?}

Several meta-analyses and reviews have compared the environmental impacts of conventional agricultural practices and sustainable agricultural practices, with a clear focus on major cereal crops and agronomic research (e.g.,[8]). A small strand of literature used ex-post quantitative studies to analyze socio-economic effects, especially labour requirements, comparing conventional and sustainable agricultural practices with a focus on Sub-Sharan African countries [11]. In analyzing the wider economic benefits from intensified agricultural production, [12] employed a partial equilibrium trade model in the case of planting multiple rice seasons a year in Bangladesh. Few studies have analyzed this question from a foresight perspective, a notable exception being [13], which did so for the case of adding potato into rice systems.

\section{What has the research found?}

Conservation agriculture has been found to considerably reduce the environmental footprint of agriculture while, at the same time, increasing agricultural production. Zero tillage practices result in significant lower carbon releases compared with conventional tillage practices for all major crops [10], leading to a $12-33 \%$ reduction of global warming potential [8].

Intensifying agricultural production by adding additional crops into existing systems has been found to have positive effects on consumption and production while creating wider economic benefits [12]. For instance, in Bangladesh, potato intensification within traditional rice-based systems has the potential to produce additional economic benefits of USD 800 million over a 20-year period [13]. The authors further note that some 6.5 million ha in Eastern Indo-Gangetic Plains alone are suitable for rice-potato system intensification. The potential for Asia in general is possibly much larger, as Map 1 suggests.

Despite obvious environmental benefits, sustainable intensification, either by adding crops or adopting conservation agricultural practices, have noticeable socio-economic trade-offs. This is especially true in labour, as higher labour demands often originate from adding crops into existing systems [13]. Conservation practices increase labour requirements, with the workload change falling more on household labour rather than paid labour, and more on women than men. Notably, however, practices such as zero/minimum tillage require less labour compared to conventional practices [11]. 


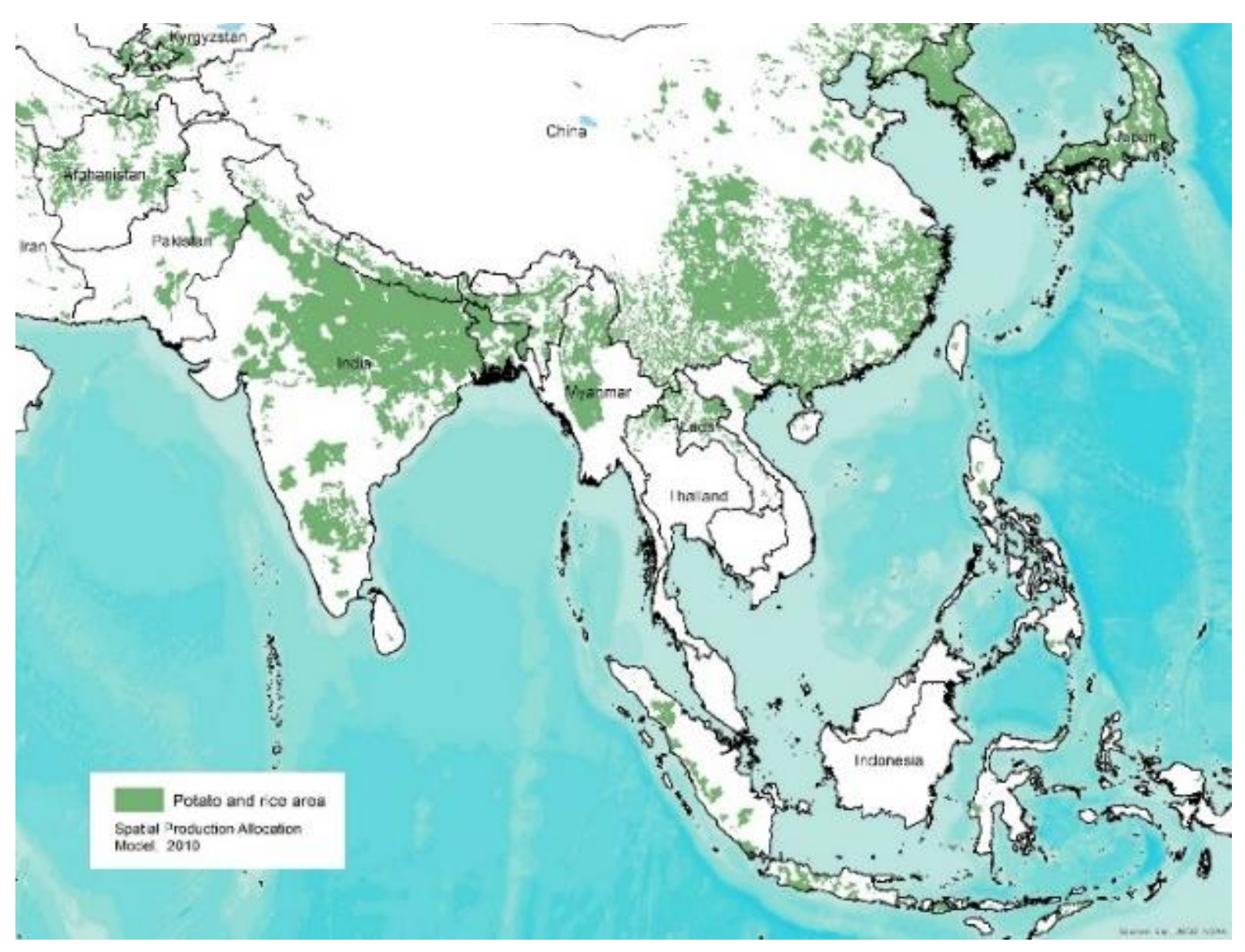

Map 1. Map showing overlapping area between rice and potato production in SE Asia in 2010 (Source: International Potato Center)

\section{What gaps deserve further work?}

Despite the potential of sustainable intensification in Asia, clear knowledge gaps exist. First, baseline data for land-use throughout the entire cropping year are generally missing or outdated, particularly for fallow land suitable for crop intensification. Second, data on the extent of adoption of conservation agricultural practices, such as minimum tillage, is based mainly on personal communication [8], or lacking altogether. This gap in land-use and adoption baseline data limits any type of rigorous and future-looking analyses. Third, we observe a strong single crop-centric focus. A systems approach is missing when analyzing how improved technologies (e.g., short duration rice and potato varieties) and conservation practices affect input-use efficiencies, especially for water, fertilizer, and pesticide requirements with forwardlooking environmental implications (e.g., soil health, water quality, carbon sequestration, etc.) at plot, landscape, and national levels. For example, research is warranted to investigate impacts of zero/minimum tillage and mulching in rice-potato systems on the carbon footprint under different agricultural regimes (i.e., conventional or conservation). Fourth, a better understanding of wider socio-economic implications and trade-offs is needed. This is especially 
true for the future of labour demand for sustainably intensified rice-potato systems: if and how much labour is available, how labour is divided between women and men, and to what extent the increased labour demand associated with adding crops can be offset, at least partly, by adopting conservation agricultural practices such as zero/minimum tillage. As profits remain a clear priority incentive for farmers to adopt any conservation farming practice, more futureoriented economic welfare analyses are required for different conservation farming practices, labour allocation scenarios, and in various countries. Fifth, there is a clear knowledge gap pertaining to appropriate policies and other incentive mechanisms that could accelerate the transition towards more sustainable intensification in potato-rice systems. Here, future-looking analyses of policies are warranted to explore implications, tradeoffs, and unintended consequences. Finally, while we observed these knowledge gaps particularly for rice-potato systems in Asia, similar gaps likely exist for various other agri-food systems across different contexts.

\section{References}

1. Knox, J., Hess, T., Daccache, A., \& Wheeler, T. (2012). Climate change impacts on crop productivity in Africa and South Asia. Environmental Research Letters, 7(3), 034032.

2. Masters, W. A., Djurfeldt, A. A., De Haan, C., Hazell, P., Jayne, T., Jirström, M., \& Reardon, T. (2013). Urbanization and farm size in Asia and Africa: Implications for food security and agricultural research. Global Food Security, 2(3), 156-165.

3. Pingali, P. 'Green revolution: Impacts, limits, and the path ahead', Proceedings of the National

4. Petsakos, A., Prager, S. D., Gonzalez, C. E., Gama, A. C., Sulser, T. B., Gbegbelegbe, S., Kikulwe, E.M. \& Hareau, G. (2019). Understanding the consequences of changes in the production frontiers for roots, tubers and bananas. Global food security (20): 180-188. Academy of Sciences of the United States of America, Vol. 109(31), (2012) pp. 12302-12308

5. Liu, Y., Pan, X., Li, J. (2015). A 1961-2010 record of fertilizer use, pesticide application and cereal yields: a review. Agronomy for sustainable development, 35(1), 83-93.

6. Vermeulen, S. J., Campbell, B. M., Ingram, J. S. (2012). Climate change and food systems. Annual review of environment and resources 37.

7. Ghimire, R., Lamichhane, S., Acharya, B. S., Bista, P., Sainju, U. M. (2017). Tillage, crop residue, and nutrient management effects on soil organic carbon in rice-based cropping systems: A review. Journal of integrative agriculture, 16(1), 1-15.

8. Jat, M. L., Chakraborty, D., Ladha, J. K., Rana, D. S., Gathala, M. K., McDonald, A., \& Gerard, B. (2020). Conservation agriculture for sustainable intensification in South Asia. Nature Sustainability, 3(4), 336-343.

9. Siopongco JDLC, Wassmann R, Sander BO. 2013. Alternate wetting and drying in Philippine rice production: feasibility study for a clean development mechanism. IRRI Technical Bulletin No. 17. Los Baños (Philippines): IRRI. 14 p.

10. Erenstein, O., \& Laxmi, V. (2008). Zero tillage impacts in India's rice-wheat systems: a review. Soil and Tillage Research, 100(1-2), 1-14.

11. Montt, G., \& Luu, T. (2020). Does Conservation Agriculture Change Labour Requirements? Evidence of Sustainable Intensification in Sub-Saharan Africa. Journal of Agricultural Economics, 71(2), 556-580.

12. Shew, A. M., Durand-Morat, A., Putman, B., Nalley, L. L., \& Ghosh, A. (2019). Rice intensification in Bangladesh improves economic and environmental welfare. Environmental Science \& Policy, 95, 46-57.

13. Gatto, M., Petsakos, A. \& Hareau, G. Sustainable Intensification of Rice-Based Systems with Potato in Eastern Indo-Gangetic Plains. Am. J. Potato Res. 97, 162-174 (2020). https://doi.org/10.1007/s12230-020-09764-6 